\title{
Introduction: Women in Asian Theatre: Conceptual, Political, and Aesthetic Paradigms
}

\author{
Arya Madhavan
}

\begin{abstract}
A conference titled Women in Asian Theatre was held at the University of Lincoln in September 2013, and papers from that gathering form the core of this issue. The rationale in organizing the conference was to explore differences across Asia and note that theories from Western feminists do not necessarily transfer to Asian models. This conference was a first step toward mapping histories of the female in Asian theatre, and this is a line of inquiry that deserves more attention.

Arya Madhavan is a senior lecturer in the School of Fine and Performing Arts, University of Lincoln, UK. She researches Indian theatre, with particular reference to kutiyattam, the oldest existing theatre form in the world today. She is also a kutiyattam performer, and her research and writing focuses on analyzing the aesthetics and praxis of kutiyattam with an intention to develop new theoretical concepts derived from its practice. Madhavan completed her PhD from the Department of Theatre, Film, and Television Studies, Aberystwyth University, in 2008, which focused on the acting and actor training of kutiyattam from the perspective of consciousness studies. Her first monograph was published in 2010, titled Kudiyattam Theatre and the Actor's Consciousness (Amsterdam: Rodolfi). Since 2012 she had been focusing on developing the research area of women in Asian theatre, and she is currently editing a Routledge anthology on the same topic.
\end{abstract}

July 2011. London. I was presenting a paper that addressed the place of women in the traditional Indian theatre form of kutiyattam at the conference Performing Arts in Contemporary Asia: Tradition and Travel. My paper generated some interest in the ways in which women actors were integrated within the two-thousand-year-old kutiyattam, the 
oldest existing theatre tradition of the world, because it was not always customary to see a female body play a female character on a public stage in several theatre traditions, Asian or otherwise. I was inspired to investigate women's place in Asian theatre practices as a result.

Although scholars have written on the role of women in individual Asian performance settings (Bailey 2012; Chatterjea 2004; Daugherty 2011; Foley 1985, 1989; Kano 2001; Mezur 2005; to name a few), I believed that a collective, concerted effort was inevitably required to generate wider scholarly interest in the topic and expand its scope. To initiate such interest, in September 2013, I organized the first international Women in Asian Theatre symposium at the University of Lincoln. More than twenty-five scholars and practitioners from the United Kingdom, India, Australia, the United States, Korea, Japan, Germany, Sweden, and France contributed. The School of Fine and Performing Arts of the University of Lincoln generously hosted the symposium, which incorporated paper presentations, lecture demonstrations, and a screening of the film of Out! Loud!, created by Betty Bernhard. The response to the CFP and the keen interest and participation from academics and practitioners were encouraging. All this proved the timely necessity of initiating research in this trajectory.

\section{Some Thoughts}

What are the larger issues concerning the nature of female roles in Asian performances? What has been done so far in order to address them? Asian theatre traditions have been an active area of study among theatre scholars and practitioners all over the world for several decades, exerting substantial influence on contemporary performance practices and actor-training methods developed since the advent of the twentieth century (Stanislavski, Grotowski, Artaud, Craig, Barba, Schechner, and Zarrilli, to name a few). However, investigating women's roles in Asian performance practices still remains marginalized. Lack of discourse constructing and generating multiple female narratives within the wider Asian performance strands is indeed a key issue. Women are often invisible in various scenarios. The politics and social syntaxes defining visibility or invisibility are varied and dependent on individual sociohistorical and cultural contexts.

The long presence of women in many performance forms also demands a thorough reassessment of the effectiveness of the current gender discourse in theorizing women's role and contributions in Asian performance contexts. Case's first line of her first chapter in the seminal Feminism and Theatre (2008) says: "From a feminist perspective, initial observations about the history of theatre noted the absence of women within the tradition" (p. 5). The problem here is the gener- 
alization of the norms of Western theatre history with regard to the universality of the female "absence" in theatre traditions as a widely applicable principle. A critical study of several Asian performance practices will directly problematize such a claim, because the "absence" of women is often not the case within Asian performance traditions. From an Indian perspective, kutiyattam, for instance, includes a mixed-gender cast, a tradition that continues today. Any kutiyattam performance, traditionally, must consist of a female cymbalist-singer, seated throughout the performance at the right side of the stage. Nangyar, the kutiyattam actress, also performs nangyarkuthu, the forty-one-day solo performance that also has had a continued existence of at least a thousand years (see Moser 2011). Nangyars enjoyed social respectability, royal patronage, and special religious provisions (including worshipping the deity by standing on the top step of the sanctum after ringing the brass bell, honors that were not extended even to women of higher castes) and these nangyars were, unlike normal women, well educated in the Sanskrit and Prakrit languages. They were never associated with prostitution, and their social position as actresses was a respectable one. L. S. Rajagopalan reiterates the Malayalam, saying "that 'one should prostate before ... a 'Nangyar who flows'" (1997: 9) (referring to a technically demanding acting convention called the "floating scene," when the actress enacts a suicidal attempt by jumping into the "river"; no one now knows the enactment of this scene) to substantiate the social respectability of the kutiyattam actress. He also speaks about the description of an all-women theatre company in the eighth-century text Kuttanimata (Advice of a Courtesan) by Damodara Gupta, who proficiently performed both male and female roles (p. 3).

Ramayana and Mahabharatha, the 200 все and 400 все Indian epics, speak about dedicated female theatre groups (vadhoo nataka sangham [female theatre group] as in Ramayana) and female dancers. Natyasastra (dated between $200 \mathrm{BCE}$ and $200 \mathrm{CE}$ ), the Indian treatise on performance, not only speaks about the necessity of including actresses in theatrical performance but also mentions the practice of the allfemale, multiroled dramatic performance called lasyam (see Madhavan 2015). Notably, all this was happening during a similar period when the mainstream male Greek theatre completely lacked any female presence among the actors or the audience. While I say this, I am well aware of the range of patriarchal Indian traditional theatres such as kathakali and yakshagana, which remained as exclusively male theatre forms. Female presence is not common in these genres even these days. But what I am trying to establish here is that one must give due consideration to more than a single phenomenon of Case's Western "absence" when analyzing the role of women in Asian theatres because 
of the complexity involved in various Asian cultural contexts and social milieus, and their historical evolution. One may find the simultaneous presence and absence of women in various Asian performances, which problematize the single conceptual lens of Western feminist theories.

Taking the Japanese example of kabuki, Okuni's role at the initial stages of the development is recognized. Okuni's creation of onna kabuki in 1600 s has arguably given birth to the theatrical tradition of onnagata (female impersonator). Okuni, according to Tsubaki, charmed the audience "by disguising herself as a man and having men impersonate women" (2001: 14). Mezur, while analyzing the unconventional and ingenious nature of Okuni's gender acts, argues that Okuni's contributions were "particularly important to the innovative gender role development of onnagata performance" (2005: 57). However, "O nna kabuki's transition to wakashu kabuki (young men kabuki) and then to yaro kabuki (men's kabuki) took place in seventeenth century" (Tsubaki 2001:13). Similar examples of female partnership and enterprise in the business of theatre/performance are manifold in several other performances of Southeast Asia, East Asia, and South Asia, and listing all of them is certainly beyond the remit of this introduction. So, "traditionally," in various Asian performances, and in almost direct opposition to the claim of Western feminist theory, there is a strongly delineable female presence. Women's genres in some cases are "alive" even today, but sadly, not universally. Female impersonation, as in cases like kabuki, replaces the female body on public stages.

In the contemporary performance scenario, of course, women engage in creative work together with and in isolation from their male counterparts. However, I also observe that if women were denied entries in certain performances such as nō, kabuki, or kathakali, for instance, such forms remain largely "women-free" even in the contemporary scenario. Women, in such cases, formulate their own female versions so as to make their mark in such performance histories, but these are not always recognized by the "mainstream" audience. The only female kathakali group that was functional in Kerala, although welcomed as an alternative to the mainstream male kathakali, is hardly considered equal to its male counterparts by the critics. Kerala Kalamandalam, the well-known Kerala kathakali school, does not admit female students into any of their kathakali specific courses even today, albeit there is no official ruling from the institution prohibiting female access to kathakali training.

The Asian modern theatres, on the other hand, offer potentials for a new and vibrant experimental space for women to carve their niche as playwrights, choreographers, performance makers, pop musicians, actors, and dancers. This divide-between the traditional puritanism 
that excludes females and the freedom offered by the contemporary performance space-is evident in various Asian countries, giving birth to a range of modern experimental female forms. Modern theatre provides a well-deserved respite for Asian women to experiment with exciting new material and spaces hitherto unavailable to them. Such female forms, as in the case of the Japanese all-female takarazuka, are either directly influenced by Western theatres or blended with Western theatre conventions so as to form unique intercultural theatres. Established in 1913 in the city of the same name, Takarazuka is considered to be Japan's most popular theatre, with women of all ages as its fans. Women play all parts, with the featured male impersonators called otakoyaku.

From a Korean perspective, Ah-Jeong Kim writes that most traditional forms in the region were performed by men, with the exception of pansori narrative singing of Korea (women allowed since the mid nineteenth century), and that the "notion of "women in theatre" largely belongs to the modern period" (2007: 845). One could argue that there are problems with the claim because evidence exists of Baudeogi-a female - as a prominent troupe leader in nansadang nori, the "all-male" performance form that existed in the Joeson dynasty's nineteenth century. The need to more fully explore the interlinkage of kiseang, female courtesan forms, with male entertainments, and the twentieth-century genesis of the female form of the Korean musical theatre, changguk, alive until the 1960s, is highly pertinent. Changguk was developed by blending the traditional pansori narrative singing of Korea and the "Japanese shinpa plays, themselves inspired by Western melodrama" (Killick 2007: 95). What I observe in the twentieth century in some countries are modern female performance engagements- the emergence of new, unique female intercultural theatre forms, as evidenced in takarazuka or changguk, which either blend local cultures with Western and/or other Asian performance styles or deliberately devise a theatre trajectory away from the "traditional" performance genres, and are influenced by Western theatre styles. The contributions made by Western women in the role of students, practitioners, and researchers in furthering this phenomenon in the post-World War II era is apparent, and, as Coldiron rightly argues, this is a largely overlooked phenomenon, one that requires better acknowledgment (2013). Curiously, the feminist intercultural theatres, as I call them, may not share the conceptual paradigms of intercultural theatre practice (e.g., Pavis's source culture versus target culture, as he explained in his Intercultural Performance Reader [1996]), because the causes for the genesis of such theatre practice is emergent from the organic female desire to find a space for "her" creative expression. In this sense, feminist intercultural 
theatre practice is a rupture in the current discourse on intercultural theatre, but one I see as a highly potent aesthetic and political paradigm in modern Asian feminist theatre practice.

Similarly, in modern choreography, Chandralekha's and Daksha Sheth's innovations in Indian dance brought about the genesis of women-authored trajectories in contemporary choreography, diffusing the stylistic barriers between various dances through their innovative performance practices. A self-proclaimed "uncompromising traditionalist" (Chatterjea 2004: 392), Chandralekha deconstructed "both the classical and neo-classical modes of Indian dance" (p. 393), subverting its mythical and mythological conventions, and idiomatically placing the female body at the center. The performance style emerging out of her movement investigation inspired by "traditional" kinetics was unique. Sheth's innovative contemporary choreography combines rhythmicity and kinetic traditions of India, such as kalaripayattu (Kerala martial arts movement) and chau (a mask dance of northeastern India with martial roots). Her dance, once rejected as pornography (Sheth 2001), has now become a landmark in contemporary Indian choreography. The contributions made by these two artists are intellectually and aesthetically momentous given the patriarchal cultural values of aesthetics and audience reception when they began their work in the late 1970s. Additionally, a large body of dramatic work by women is taking place away from the mainstream in various Asian countries, but documentation and acknowledgment in organized public forums is lacking, making these efforts largely invisible to the wider world.

Thus, I argue that current feminist theoretical propositions, such as Sue-Ellen Case's, are often insufficient to deal with the visibility/invisibility of Asian women on Asian stages. The sociocultural contexts from which these performances emanate are divergent from Western contexts. We require more than a monocultural model of feminism in order to situate the culture, politics, and history of female presence/absence in various Asian scenarios. Furthermore, the performance genres in Asia vary from ritualistic trance dances to highly stylized performance models. Women's presence or absence is culturally modulated by each individual performance genre (folk, ritualistic, domestic, classical, etc.) within any given larger cultural and geographical context (such as India or Japan or Korea). Only more comprehensive and localized feminist models relating to individual cultural, historical, and geographical contexts can sufficiently address the place of women in Asian performances. It was such thoughts that I held, knowingly or unknowingly, when I organized the conference Women in Asian Theatre in 2013. 


\section{Conference}

Although the event was initially planned as a one-day symposium, an extra half day had to be added, owing to the strong interest. The academic rigor of the papers, the variety of issues that they addressed, and the dedication of the conference participants were the reasons behind the success. The conference was inaugurated by Kathy Foley, who spoke about the need for such a conference and what she hoped that the conference would do to generate debates on the topic. What followed were two highly meaningful lecture demonstrations, one by Tokuro Miyake X, one of the two professional Japanese female kyogen performers, and the other by kathak dancer Sonia Sabri (UK), with an introduction by Stacey Prickett. Miyake, from the Izumi school of kyogen, was initiated by her grandfather, Tokuro Miyake IX, and became his successor. She and her sister became the first female performers in kyogen's seven-hundred-year history. Miyake's lecturedemonstration epitomized the ambitions set by the conference: She represented the role that women are increasingly attempting in the long history of patriarchal performances.

Three papers addressing gender politics in Korean cotemporary musical theatre, Japanese shirabyoshi performance, and an analysis of eco-feminism and bharatanatyam, all featured in the new scholars panel, mapped the emergent themes addressed by upcoming doctoral theses. The debates that followed the panel were supportive to the students in further formulating their ideas.

Kathy Foley in her keynote addressed several questions that were relevant to my discussion above. She asks,

Must the woman be performed by a male to be artful, and why is "herstory" melodrama, while "his-tory," high art? What spaces were allowed women in actual practice for women, and is a class a factor? How were "goddess" and "courtesan" reconfigured in postcolonial practices? What does the rise of more conservative societies in a neoliberal economic era mean for women as actual performers? As forms that were once "all-female" become "gender straight," what was lost and what is gained, and how have interfaces with Western women in intercultural work supported or distorted the scene? (2013)

While all these questions are highly relevant to the larger context of issues that are addressed by the conference, it is the very first question that interests me the most, because I believe that it addresses the dichotomy of the real versus construct with regard to the female subjectivity presented and perceived on public stages. It is not unusual to hear from the audience of traditional performances that the "real" woman 
enacting the female characters often fails to portray womanhood as artfully as it is represented by the female impersonator. Foley's discussion as above is all the more relevant in the particular performance context of Asian theatres, because female impersonation is a highly developed art in several Asian classical and folk performances. The day ended with the film Out! Loud! produced and directed by Betty Bernhard in 2013. This work is about the LGBT community of India that "that draws parallels between ancient and sacred Indian stories, such as the Puranas and the Mahabharata, wherein representations of homosexuality, bisexuality, lesbianism, transgender, and transsexual activity are clearly described" (Bernhard 2013). This deeply touching film, which sensitively looked into the lives of the young LGBT people, successfully captured the struggles that they face in Indian society, which does not accommodate a third sex into its strict binary gender structure. Anna Morcom, an academic specializing in this area, moderated the postshow discussion between the conference participants and Bernhard.

The second day of the conference hosted a range of papers. The first panel, "(Radical) Degenerate Bodies and Spaces in Noh, Butoh, and Performance Art by Japanese Women," had three papers and addressed the impact of female presence in $n \bar{o}$, their efforts to gain an equal standing with their male counterparts, and studies of the performance tactics of women in butō and contemporary performance art. What struck me the most was the effort made by the women in each of those specific contexts to demand better artistic and social recognition of their work. The next panel, on women in Indian theatre, addressed the position of women mainly from a modern perspective. Scholars spoke about aesthetic innovations by women in modern Indian theatre as well as the lack of acknowledgment of female labor when it comes to tracing theatre history. Further papers were presented on female interaction with the Balinese topeng performance, the fear of female sexuality and its impact upon Japanese performances, analysis of a particular female innovation in nangyarkuthu, and Cambodian and Korean allwomen performance genres. The topeng panel examined the "dynamic interaction between Western and Balinese performers ... [with a particular focus on] the most interesting and least examined elements ... [of] the interaction of 'Western' female performers with Balinese topeng and the subsequent emergence of female topeng performers in Bali" (Coldiron 2013). I had touched upon the benefits of such interactions when I wrote about the feminist intercultural theatre in an earlier paragraph.

Sudha Bhuchar, then the artistic director of London's Tamasha Theatre Company, delivered the second keynote speech. Bhuchar had been an active member of the diaspora Asian theatre in Britain 
since late 1970s and represented this perspective as she spoke avidly about her experience of leading Tamasha for twenty-five years. This conference successfully mapped scholarly engagement in retracing the female trajectory, often lost and often alive, in Asian performances.

\section{The Special Issue}

The fundamental concepts underpinning seven of the nine essays appearing in this special issue were presented at the 2013 conference. The nine essays and a performance review that are featured in this special issue attempt to map, reconstruct, and debate performance histories and practices of Asian women in both contemporary and historical settings from Japan, India, Taiwan, Cambodia, Indonesia, and South Korea. The authors analyze the artistic engagement of women as actors, activists, directors, and performance makers.

In the specific Asian context, an initial examination of the ground so as to generate multiple female narratives, in contrast to their conceptual exploration, seems to be a priority. Therefore, some of the essays in this issue, such as Nut's "Lokhon Luang, the Cambodian Court Theatre: Toward a Decline of Women's Supremacy?" and Tuan's “Taiwanese Jingju Performances Featuring Women's Writing: Meng Xiaodong and The Ghostdom River," map the territory rather than engaging in a theoretical debate on "her" presence, emphasising the need for reportage, documentation, and, indeed, acknowledgment of "her" role. Taking Nut's essay an example, I wonder whether the current feminist theoretical discourse can sufficiently comprehend the historical "presence" of the female body in the public sphere and "her" dominance in defining its aesthetic characteristics, as is exemplified by the artistic dominance and the creative decisions exerted by Queen Sissowath Kossomak (1907-1975) and Princess Norodom Buppha Devi (1943-) in Khmer lakhoun luang since the early nineteenth century, because the historical "absence" of women had been the fundamental theoretical position of Western feminist discourse. However, in Western theatre, women have not been absent altogether from theatre since the period of commedia dell'arte in the sixteenth century and the Restoration period (1660 onward) in Britain. But the social position of the actress in the Restoration period was indeed tainted with prostitution and sexual promiscuity. Such issues of course are not part of the Khmer situation, where performers were the elite women of the royal family.

The essays featured in this special issue examine the nature of female visibility and women's contributions to Asian theatre. If the concerns around waning gender exclusivity of the all-female Cambodian court theatre lokhon luang, as men took over the monkey roles after World War II and now assume giant roles, is raised in Nut's essay, 
the lack of acknowledgment of female labor is the issue addressed by Purkayastha in the history of IPTA in India. Similarly, Gabrovska and Geilhorn aim to map a trajectory of the female presence on the predominantly all-male public stages of Japan with particular reference to kabuki and no. . Orenstein's essay on women's role in female puppetry argues that the future of some of the traditional forms on puppetry from Kerala, such as nokku vidya pava kali (eye skill puppetry) and tholpavakkuthu (shadow puppetry), currently lie safely in the hands of young women, owing to social and economic factors. Here the author elaborates how the tradition, which generates strict rules about male and female roles, itself is a volatile category that self-adapts according to changing times. Overall, the investigations and debates presented in these essays are passionate, interrogatory, and organic. This special issue is an attempt to map the territory of women's role in Asian theatres.

And finally, I thank Kathy Foley, who gave me the wonderful opportunity to edit a special issue for the reputed Asian Theatre Journal on the topic. I am grateful for the trust that she vested upon my capacities.

\section{REFERENCES}

Bailey, Paul. 2012.

Women and Gender in Twentieth-Century China. Gender and History. London: Palgrave.

Bernhard, Betty. 2013.

Abstract submitted to the International Conference on Women in Asian Theatre, University of Lincoln, 13-14 September.

Coldiron, Margaret. 2013.

Panel proposal submitted to the International Conference on Women in Asian Theatre, University of Lincoln, 13-14 September.

Case, Sue-Ellen. [1988] 2008.

Feminism and Theatre. London: Palgrave Macmillan.

Chatterjea, Ananya. 2004.

Butting Out: Reading Resistive Choreographies through Works by Jawole Willa Jo Zollar and Chandralekha. Middletown, CT: Wesleyan University Press.

Daugherty, Diane. 2011.

"Subhadra Redux: Reinstating Female Kutiyattam." In Between Fame and Shame: Performing Women-Women Performers in India, ed. Heidrun Brückner, Hanne de Bruin, and Heike Moser, 153-167. Wiesbaden: Harrassowitz.

Foley, Kathy. 1985.

"Dancer and the Danced: Trance Dance and Theatrical Performance in West Java," Asian Theatre Journal 2, no. 1: 28-49. 
1989.

"Of Gender and Dance in Southeast Asia: From Goddess to Go-Go Girl," In Progress and Possibilities: CORD 20th Anniversary Conference, Oct. 9-11, 1987: Proceedings and Papers, ed. Ruth Abrahams. Cambridge, MA: Congress on Research in Dance.

2013.

"The Woman Thing: Issues and Advances for Women in Southeast Asian Traditions." Paper presented at the International Conference on Women in Asian Theatre, University of Lincoln, 13 September.

Kano, Ayako. 2001.

Acting like a Woman in Modern Japan: Theater, Gender, and Nationalism. London: Palgrave Macmillan.

Killick, Andrew. 2007.

"Changguk." In Encyclopedia of Asian Theatre, ed. Samuel L. Leiter, 95-96. Westport, CT: Greenwood Press.

Kim, Ah-Jeong. 2007.

"Women in Asian Theatre: Korea." In Encyclopedia of Asian Theatre, ed. Samuel L. Leiter, 845-846. Westport, CT: Greenwood Press.

Madhavan, Arya. 2015.

"Actor's Imagination: Kutiyattam and the Natyasastra." In The Natyasastra and the Body in Performance: Essays on Indian Theories of Dance and Drama, ed. Sreenath Nair, 182-195. Jefferson, NC: McFarland.

Mezur, Katherine. 2005.

Beautiful Boys/Outlaw Bodies: Devising Kabuki Female-Likeness. London: Palgrave Macmillan.

Moser, Heike. 2011.

"How Kutiyattam Became Kuti-Attam: The Changing Role of Women in the Kutiyattam Tradition of Kerala." In Between Fame and Shame: Performing Women-Women Performers in India, ed. Heidrun Brückner, Hanne de Bruin, and Heike Moser, 169-188. Wiesbaden: Harassowitz.

Pavis, Patrice. 1996.

The Intercultural Performance Reader. London: Routledge.

Rajagopalan, L. S. 1997.

Women's Role in Kudiyattam. Chennai: Kuppuswami Sastry Research Institute.

Sheth, Daksha. 2001.

"Daksha Sheth: My Journey in Dance." Narthaki (website), http:// www.narthaki.com/info/intervw/intrvw18.html, accessed 9 February 2015.

Tsubaki, Andrew. 2001.

"The Performing Arts of Sixteenth Century Japan: A Prelude to Kabuki." In A Kabuki Reader: History and Performance, ed. Samuel L. Leiter, 3-16. London: Routledge. 